\title{
Effects of Baseline Blood Pressure and Low-Density Lipoprotein Cholesterol on Safety and Efficacy of Canagliflozin in Japanese Patients with Type 2 Diabetes Mellitus
}

Nobuya Inagaki · Maki Goda $\cdot$ Shoko Yokota · Nobuko Maruyama •

Hiroaki Iijima

To view enhanced content go to www.advancesintherapy.com

Received: September 14, 2015 / Published online: November 3, 2015

(c) The Author(s) 2015. This article is published with open access at Springerlink.com

\section{ABSTRACT}

Introduction: Sodium glucose co-transporter 2 inhibitors decrease hemoglobin A1c (HbA1c) and blood pressure (BP) and slightly increase low-density lipoprotein cholesterol (LDL-C) in patients with type 2 diabetes mellitus (T2DM). The effects of baseline BP and LDL-C on the safety and efficacy of canagliflozin in patients were analyzed post hoc in a phase III study.

Methods: Japanese patients with T2DM were classified by baseline systolic BP (SBP) of $<130$ or $\geq 130 \mathrm{mmHg}$, diastolic BP (DBP) of $<80$ or $\geq 80 \mathrm{mmHg}$, and LDL-C of $<120$ or $\geq 120 \mathrm{mg}$ / dL. Canagliflozin was administered daily to patients for 52 weeks at doses of either $100 \mathrm{mg}$

Electronic supplementary material The online version of this article (doi:10.1007/s12325-015-0255-8) contains supplementary material, which is available to authorized users.

\section{N. Inagaki}

Department of Diabetes, Endocrinology and Nutrition, Kyoto University Graduate School of Medicine, Kyoto, Japan

M. Goda $(\bowtie) \cdot$ S. Yokota $\cdot$ N. Maruyama $\cdot$ H. Iijima Mitsubishi Tanabe Pharma Corporation, Tokyo, Japan

e-mail: gouda.maki@mm.mt-pharma.co.jp
( $n=584)$ or $200 \mathrm{mg}(n=715)$. The effects of canagliflozin on the incidence of adverse events (AEs), BP, and LDL-C were evaluated.

Results: No clear differences were observed in overall safety among the subgroups classified by baseline SBP, DBP, or LDL-C, except for a slight imbalance in AEs associated with volume depletion with $200 \mathrm{mg}$ of canagliflozin. The decrease in mean SBP and DBP was evident in subgroups with baseline SBP $\geq 130 \mathrm{mmHg}$ and DBP $\geq 80 \mathrm{mmHg}$. Mean LDL-C was decreased in subgroups with baseline LDL-C $\geq 120 \mathrm{mg} / \mathrm{dL}$ at both canagliflozin doses, and they were slightly increased, but did not exceed $120 \mathrm{mg} / \mathrm{dL}$ in subgroups with baseline LDL-C $<120 \mathrm{mg} / \mathrm{dL}$. The changes in HbA1c and body weight from those observed at baseline were not different between subgroups classified by SBP, DBP, and LDL-C at either dose.

Conclusion: The present post hoc analysis indicates that canagliflozin is well tolerated irrespective of baseline $\mathrm{BP}$ and LDL-C in patients with T2DM.

Trial registration: ClinicalTrials.gov identifier, NCT01387737.

Funding: Mitsubishi Tanabe Pharma Corporation. 
Keywords: Blood pressure; Canagliflozin; Low-density lipoprotein cholesterol (LDL-C); Sodium glucose co-transporter 2 (SGLT2) inhibitor; Type 2 diabetes mellitus; Volume depletion

\section{INTRODUCTION}

Patients with type 2 diabetes mellitus (T2DM) often have comorbid hypertension and hypercholesterolemia. Comorbidities of these diseases synergistically increase the incidence rates of cerebrovascular and coronary heart diseases [1-4]. Integrated control of body weight, blood pressure (BP), and serum lipids in addition to blood glucose is essential for the treatment of diabetic patients to decrease the risk of cardiovascular (CV) events [5-7], because the goal of diabetes treatment is to improve quality of life and life span of diabetic patients to the same level as those of non-diabetics [8]. Sodium glucose co-transporter 2 (SGLT2) inhibitors are anti-diabetic agents that correct hyperglycemia by promoting urinary glucose excretion through the inhibition of glucose reabsorption in proximal tubules irrespective of the patient's insulin secretory capacity or insulin resistance. Because this underlying pharmacological mechanism is novel and clearly different from that of existing drugs, SGLT2 inhibitors may present a new treatment option for T2DM.

In various clinical trials in patients with T2DM, administration of SGLT2 inhibitors, including canagliflozin, resulted in a sustained decrease in hemoglobin A1c (HbA1c), body weights, and BP for long periods [9-14]. Recently, in the EMPA-REG OUTCOME trial (ClinicalTrials.gov identifier, NCT01131676), empagliflozin significantly reduced the rate of primary composite CV outcome and of death from any cause in patients with T2DM at high $\mathrm{CV}$ risk [15]. It was the first evidence to assess the effects of SGLT2 inhibitor on CV outcome. The mechanisms behind the $\mathrm{CV}$ benefits of empagliflozin are multidimensional and involve established changes, such as decreasing HbA1c, losing body weight and lowering BP. On the other hand, BP-lowering effects of SGLT2 inhibitors may be mediated at least partly by its diuretic effect, and there is a concern of the risk of dehydration and hypotension. It has been reported that SGLT2 inhibitors increase low-density lipoprotein cholesterol (LDL-C) as a class effect [16, 17]. Although small increase in high-density lipoprotein cholesterol (HDL-C) was also observed in patients with T2DM, increase in LDL-C raises concerns of a CV risk [10].

Therefore, we investigated the influence of different baseline BPs and LDL-C (as CV risk factors) on the safety and efficacy of canagliflozin by post hoc analysis of data in a 52-week phase III study [13] in Japanese patients with T2DM.

\section{METHODS}

\section{Study Design and Patient Population}

The present post hoc subgroup analyses were conducted using the data obtained in a phase III study of canagliflozin in Japanese patients with T2DM (multicenter, open-label, and long-term administration) [13]. In this clinical study, canagliflozin was administered once daily for 52 weeks at 100 or $200 \mathrm{mg}$ as monotherapy or as add-on therapy to other oral antihyperglycemic drugs (sulfonylurea, glinide, $\alpha$-glucosidase inhibitor, biguanide, thiazolidinedione, or dipeptidylpeptidase-4 inhibitor). The study was conducted in patients with T2DM whose 
blood glucose was inadequately controlled with diet/exercise therapy alone or in combination with an oral antihyperglycemic drug for more than 12 weeks before screening. The complete inclusion and exclusion criteria are described in the original report [13]. The main inclusion criteria were (1) patients $\geq 20$ years of age, (2) diagnosis of T2DM at least 3 months before the screening, and (3) HbA1c of $\geq 7.0 \%$ and $\leq 10.0 \%$ in monotherapy and of $\geq 7.0 \%$ and $\leq 10.6 \%$ in combination therapy. The main exclusion criteria were (1) systolic BP (SBP) of $\geq 160 \mathrm{mmHg}$ and diastolic BP (DBP) of $\geq 100 \mathrm{mmHg}$ during the run-in period, (2) estimated glomerular filtration rate (eGFR) of $<50 \mathrm{~mL} / \mathrm{min} / 1.73 \mathrm{~m}^{2}$ at the beginning of the run-in period, (3) urinary albumin-to-creatinine ratios of $\geq 300 \mathrm{mg} / \mathrm{g}$ creatinine, and (4) triglyceride of $\geq 600 \mathrm{mg} / \mathrm{dL}$ on the screening day.

This clinical study was conducted in compliance with Guideline for Good Clinical Practice and the Pharmaceutical Affairs Law in Japan. All procedures followed were in accordance with the ethical standards of the responsible committee on human experimentation (institutional and national) and with the Helsinki Declaration of 1964, as revised in 2013. Informed consent was obtained from all patients for being included in the study. This study is registered on ClinicalTrials.gov, identifier NCT01387737.

In the present analyses, patients were classified into subgroups according to their baseline BP or LDL-C: patients with baseline SBP $<130 \mathrm{mmHg}(S<130)$ and SBP $\geq 130 \mathrm{mmHg}$ $(S \geq 130)$, patients with DBP $<80 \mathrm{mmHg}$ $(D<80)$ and DBP $\geq 80 \mathrm{mmHg}(D \geq 80)$, and patients with LDL-C $<120 \mathrm{mg} / \mathrm{dL}(L<120)$ and LDL-C $\geq 120 \mathrm{mg} / \mathrm{dL}(L \geq 120)$. SBP $<130 \mathrm{mmHg}$, DBP $<80 \mathrm{mmHg}$, and LDL-C $<120 \mathrm{mg} / \mathrm{dL}$ are the control target levels for SBP, DBP, and LDL-C in Evidence-based Practice Guideline for the Treatment for Diabetes in Japan 2013 [8].

\section{Assessments}

\section{Safety}

Adverse events (AEs) were recorded throughout the study, as described in the original report [13], and the results for each subgroup are presented in this report. AEs were classified according to the System Organ Class and preferred term of MedDRA/J version 15.1 (Japanese Maintenance Organization, Tokyo, Japan). Drug-related AEs were defined as AEs in which a causal relationship with canagliflozin was not denied. We also evaluated the change of laboratory variables from baseline to week 52 (hemoglobin, hematocrit, aspartate transaminase (AST), alanine transaminase (ALT), $\gamma$-glutamyltranspeptidase $(\gamma \mathrm{GTP})$, blood urea nitrogen $(\mathrm{BUN}), \mathrm{Na}, \mathrm{K}, \mathrm{Cl}, \mathrm{Ca}, \mathrm{Mg}$, and inorganic phosphate; eGFR; and heart rate) in each subgroup.

\section{Efficacy}

Changes in HbA1c, fasting plasma glucose (FPG), and body weight from baseline to week 52 were assessed in each subgroup. The changes in SBP or DBP over the treatment period with the study drug and the change from baseline at week 52 were evaluated in each subgroup according to SBP or DBP categories. In addition, the proportion of patients whose SBP decreased to $<130 \mathrm{mmHg}$ and those in whom DBP decreased to $<80 \mathrm{mmHg}$ were determined in original $S \geq 130$ and $D \geq 80$ groups, respectively.

The changes in lipid parameters such as LDL-C, triglyceride, HDL-C, and LDL-C/HDL-C from baseline to week 52 and the changes in LDL-C over the treatment period with the study drug were assessed in each LDL-C subgroup. LDL-C was quantified using the direct method. 


\section{Statistical Analysis}

All the analyses were conducted for both doses of canagliflozin. Safety analyses were performed in the safety analysis set $(N=1299)$, which comprised all patients excluding those who did not receive a dose of canagliflozin or who lacked safety data after starting the study drug. AEs were summarized as the number and percentage of patients with AEs. Laboratory variables were shown as the mean \pm standard deviation (SD) for the change from the baseline to week 52 . Only patients with data at both baseline and week 52 or the relevant visit were included in the analyses of safety variables. Statistical analyses were not performed on the safety and laboratory variables between the subgroups.

Efficacy analyses were performed in the full analysis set $(N=1297)$, which comprised all allocated patients, excluding those without T2DM, those not receiving a dose of the study drug, or those for whom efficacy data after starting the study drug administration was absent. The last observation carried forward method was used to impute missing data at week 52. The changes in HbA1c, FPG, body weight, SBP, DBP, LDL-C, triglyceride, HDL-C, and LDL-C/HDL-C from baseline to week 52 were analyzed using the one-sample $t$ test. All statistical tests were performed two-sided at a 5\% significance level. For all statistical analysis, SAS ver. 9.2 (SAS Institute Inc., Cary, NC, USA) was used.

\section{RESULTS}

\section{Analysis in Subgroups Classified by Baseline BP}

Patient characteristics of subgroups classified by baseline BP are shown in Table 1. In patients treated with 100 or $200 \mathrm{mg}$ canagliflozin, the number of patients in the $S<130$ subgroup was almost the same as that in the $S \geq 130$ subgroup and the number of patients in the $D<80$ subgroup was slightly larger than that of the $D \geq 80$ subgroup.

Table 2 summarizes the incidence rates of AEs. We have focused on AEs with $\geq 2$ times difference in the incidence rate between subgroups. No clear difference was observed in the incidence rate of total AEs between subgroups classified by baseline SBP and DBP at both doses of canagliflozin. There were no clear differences in the incidence rates of serious AEs (SAEs) between subgroups in the $100 \mathrm{mg}$ treated group. Whereas a higher incidence rate of SAEs was observed in $S \geq 130$ subgroup at the $200 \mathrm{mg}$ dose, the frequency of drug-related SAEs was low and similar between $S \geq 130$ and $S<130$ subgroups [see Table 11 in the electronic supplementary material (ESM)]. The frequency of AEs leading to study discontinuation was low among subgroups. There was a difference in the incidence rates of urinary tract infection between the subgroups at $200 \mathrm{mg}$ canagliflozin dose. The frequencies of urinary tract infection-related AEs were $4.0 \%$ and $0.3 \%$ in $S<130$ and $S \geq 130$ subgroups, respectively, and $3.5 \%$ and $0.6 \%$ in $D<80$ and $D \geq 80$ subgroups, respectively.

The incidence rate of volume depletion-related AEs was similar across subgroups at the $100 \mathrm{mg}$ dose. In contrast, there was an imbalance in the $\mathrm{AE}$ incidences between subgroups classified by SBP and DBP at the $200 \mathrm{mg}$ dose. The frequency of AEs was $2.9 \%$ and $1.2 \%$ in $S<130$ and $S \geq 130$ subgroups, respectively, and $2.8 \%$ and $1.3 \%$ in $D<80$ and $D \geq 80$ subgroups, respectively.

Volume depletion-related AEs occurred in 15 patients receiving the $200 \mathrm{mg}$ dose. Of these, eight had mild postural dizziness: seven 
Table 1 Demographics and baseline characteristics of patients in subgroups classified by baseline BP

\begin{tabular}{|c|c|c|c|c|c|c|}
\hline \multirow[t]{2}{*}{ Dose } & \multirow[t]{2}{*}{ Characteristics } & \multirow[t]{2}{*}{ Total } & \multicolumn{2}{|l|}{ SBP } & \multicolumn{2}{|l|}{ DBP } \\
\hline & & & $<130 \mathrm{mmHg}$ & $\geq 130 \mathrm{mmHg}$ & $<80 \mathrm{mmHg}$ & $\geq 80 \mathrm{mmHg}$ \\
\hline \multirow[t]{21}{*}{$100 \mathrm{mg}$} & Number of patients & 584 & 295 & 289 & 334 & 250 \\
\hline & \multicolumn{6}{|l|}{ Sex* } \\
\hline & Male & $421(72.1)$ & $206(69.8)$ & $215(74.4)$ & $220(65.9)$ & $201(80.4)$ \\
\hline & Female & $163(27.9)$ & $89(30.2)$ & $74(25.6)$ & $114(34.1)$ & $49(19.6)$ \\
\hline & Monotherapy* & $127(21.7)$ & $67(22.7)$ & $60(20.8)$ & $72(21.6)$ & $55(22.0)$ \\
\hline & Combination therapy* & $457(78.3)$ & $228(77.3)$ & $229(79.2)$ & $262(78.4)$ & $195(78.0)$ \\
\hline & With diabetic complications ${ }^{* \dagger}$ & $176(30.1)$ & $82(27.8)$ & $94(32.5)$ & $103(30.8)$ & $73(29.2)$ \\
\hline & With hypertension* & $315(53.9)$ & $105(35.6)$ & $210(72.7)$ & $144(43.1)$ & $171(68.4)$ \\
\hline & With antihypertensive agents* & $202(34.6)$ & $77(26.1)$ & $125(43.3)$ & $105(31.4)$ & $97(38.8)$ \\
\hline & \multicolumn{6}{|l|}{ Concomitant antihypertensive } \\
\hline & $\mathrm{ACE}^{*}$ & $22(3.8)$ & $8(2.7)$ & $14(4.8)$ & $11(3.3)$ & $11(4.4)$ \\
\hline & $\mathrm{ARB}^{*}$ & $167(28.6)$ & $64(21.7)$ & $103(35.6)$ & $86(25.7)$ & $81(32.4)$ \\
\hline & Diuretic* $^{*}$ & $16(2.7)$ & $4(1.4)$ & $12(4.2)$ & $4(1.2)$ & $12(4.8)$ \\
\hline & With dyslipidemia* & $445(76.2)$ & $220(74.6)$ & $225(77.9)$ & $244(73.1)$ & $201(80.4)$ \\
\hline & Age (years) ${ }^{t}$ & $57.5[10.7]$ & $56.6[10.8]$ & $58.5[10.5]$ & $59.1[10.7]$ & $55.4[10.3]$ \\
\hline & Duration (years) ${ }^{\ddagger}$ & $6.45[5.93]$ & $6.48[6.26]$ & $6.43[5.59]$ & $7.16[6.19]$ & $5.50[5.44]$ \\
\hline & Body weight $(\mathrm{kg})^{\ddagger}$ & $70.44[15.56]$ & $68.80[15.51]$ & $72.12[15.46]$ & $66.70[14.76]$ & $75.45[15.22]$ \\
\hline & Body mass index $\left(\mathrm{kg} / \mathrm{m}^{2}\right)^{1}$ & $25.89[4.65]$ & $25.26[4.58]$ & $26.52[4.65]$ & $25.01[4.43]$ & $27.05[4.69]$ \\
\hline & HbAlc $(\%)^{*}$ & $8.05[0.88]$ & $8.09[0.91]$ & $8.01[0.85]$ & $8.09[0.93]$ & $8.00[0.81]$ \\
\hline & $\mathrm{FPG}(\mathrm{mg} / \mathrm{dL})^{\ddagger}$ & $158.9[35.3]$ & $157.1[35.3]$ & $160.8[35.3]$ & $157.2[35.9]$ & $161.3[34.5]$ \\
\hline & $\mathrm{eGFR}\left(\mathrm{mL} / \mathrm{min} / 1.73 \mathrm{~m}^{2}\right)^{\ddagger}$ & $85.1[18.5]$ & $85.1[18.2]$ & $85.0[18.8]$ & $85.4[18.0]$ & $84.7[19.2]$ \\
\hline \multirow[t]{9}{*}{$200 \mathrm{mg}$} & Number of patients & 715 & 378 & 337 & 395 & 320 \\
\hline & \multicolumn{6}{|l|}{ Sex ${ }^{*}$} \\
\hline & Male & $503(70.3)$ & $263(69.6)$ & $240(71.2)$ & $248(62.8)$ & $255(79.7)$ \\
\hline & Female & $212(29.7)$ & $115(30.4)$ & $97(28.8)$ & $147(37.2)$ & $65(20.3)$ \\
\hline & Monotherapy* & $253(35.4)$ & $145(38.4)$ & $108(32.0)$ & $154(39.0)$ & $99(30.9)$ \\
\hline & Combination therapy* & $462(64.6)$ & $233(61.6)$ & $229(68.0)$ & $241(61.0)$ & $221(69.1)$ \\
\hline & With diabetic complications ${ }^{* \dagger}$ & $211(29.5)$ & $98(25.9)$ & $113(33.5)$ & $110(27.8)$ & $101(31.6)$ \\
\hline & With hypertension* & $375(52.4)$ & $128(33.9)$ & $247(73.3)$ & $164(41.5)$ & $211(65.9)$ \\
\hline & With antihypertensive agents* & $238(33.3)$ & $96(25.4)$ & $142(42.1)$ & $126(31.9)$ & $112(35.0)$ \\
\hline
\end{tabular}


Table 1 continued

\begin{tabular}{|c|c|c|c|c|c|c|}
\hline \multirow[t]{2}{*}{ Dose } & \multirow[t]{2}{*}{ Characteristics } & \multirow[t]{2}{*}{ Total } & \multicolumn{2}{|l|}{ SBP } & \multicolumn{2}{|l|}{ DBP } \\
\hline & & & $<130 \mathrm{mmHg}$ & $\overline{\geq 130 \mathrm{mmHg}}$ & $<80 \mathrm{mmHg}$ & $\geq 80 \mathrm{mmHg}$ \\
\hline & \multicolumn{6}{|l|}{ Concomitant antihypertensive } \\
\hline & $\mathrm{ACE}^{*}$ & $30(4.2)$ & $9(2.4)$ & $21(6.2)$ & $12(3.0)$ & $18(5.6)$ \\
\hline & $\mathrm{ARB}^{*}$ & $196(27.4)$ & $82(21.7)$ & $114(33.8)$ & $108(27.3)$ & $88(27.5)$ \\
\hline & Diuretic* & $12(1.7)$ & $4(1.1)$ & $8(2.4)$ & $7(1.8)$ & $5(1.6)$ \\
\hline & With dyslipidemia* & $538(75.2)$ & $282(74.6)$ & $256(76.0)$ & $298(75.4)$ & $240(75.0)$ \\
\hline & Age (years) ${ }^{*}$ & $57.9[11.1]$ & $56.3[11.3]$ & $59.6[10.6]$ & $59.4[11.3]$ & $55.9[10.5]$ \\
\hline & Duration (years) & $5.99[5.67]$ & $6.03[5.85]$ & $5.95[5.47]$ & $6.54[6.14]$ & $5.32[4.96]$ \\
\hline & Body weight $(\mathrm{kg})^{\ddagger}$ & $69.74[14.64]$ & $69.05[15.01]$ & $70.51[14.20]$ & $66.34[13.65]$ & $73.94[14.76]$ \\
\hline & Body mass index $\left(\mathrm{kg} / \mathrm{m}^{2}\right)^{*}$ & $25.74[4.37]$ & $25.33[4.45]$ & $26.19[4.25]$ & $24.87[4.09]$ & $26.81[4.49]$ \\
\hline & HbAlc $(\%)^{*}$ & $8.09[0.86]$ & $8.08[0.87]$ & $8.10[0.86]$ & $8.04[0.86]$ & $8.15[0.87]$ \\
\hline & FPG $(\mathrm{mg} / \mathrm{dL})^{\star}$ & $159.0[34.4]$ & $161.1[35.9]$ & $156.7[32.6]$ & $157.3[34.9]$ & $161.1[33.8]$ \\
\hline & $\operatorname{eGFR}\left(\mathrm{mL} / \mathrm{min} / 1.73 \mathrm{~m}^{2}\right)^{t}$ & $85.6[18.2]$ & $86.7[18.2]$ & $84.4[18.1]$ & $84.3[18.0]$ & $87.2[18.2]$ \\
\hline
\end{tabular}

$A C E$ angiotensin-converting enzyme inhibitor, $A R B$ angiotensin II receptor blocker, $B P$ blood pressure, $D B P$ diastolic blood pressure, $e G F R$ estimated glomerular filtration rate, $F P G$ fasting plasma glucose, $H b A 1 c$ hemoglobin Alc, $S B P$ systolic blood pressure

* Data are presented as the $n(\%)$ of patients

$\dagger$ Diabetic nephropathy, diabetic neuropathy, and diabetic retinopathy

* Data are presented as the mean [standard deviation]

patients with postural dizziness were in the $S<130$ and $D<80$ subgroups. Four had mild or moderate dehydration: two patients were with $S<130$ and $D<80$ and two patients were with $S \geq 130$ or $D \geq 80$ subgroups (data not shown).

The incidence of other AEs including hypoglycemia (including both symptomatic and asymptomatic hypoglycemia), genital infections, osmotic diuresis, and skin and subcutaneous tissue disorders was similar across subgroups. The incidence rate of CV-related AEs was also similar between subgroups at both doses, and moderate lacunar infarction and mild increase of creatine phosphokinase occurred in one event each at 100 and $200 \mathrm{mg}$, respectively, and were classified as drug-related CV events.
Changes in laboratory variables from baseline to week 52 were similar across subgroups (see Table S2 in the ESM). Hematocrit and BUN increased across subgroups. No changes from baseline in electrolytes ( $\mathrm{Na}, \mathrm{K}, \mathrm{Cl}, \mathrm{Ca}, \mathrm{Mg}$, and inorganic phosphate) and heart rate were observed in any subgroups at both canagliflozin doses.

HbA1c, FPG and body weight were significantly decreased from baseline to week 52 of treatment with canagliflozin in all subgroups (Table 3). The decreases in mean SBP and DBP from the baseline at 52 weeks were larger in $S \geq 130$ and $D \geq 80$ subgroups than those in $S<130$ and $D<80$ subgroups, respectively (Table 3 ). The decreases in mean SBP and DBP in $S \geq 130$ and $D \geq 80$ subgroups were sustained from 4 to 52 weeks after 


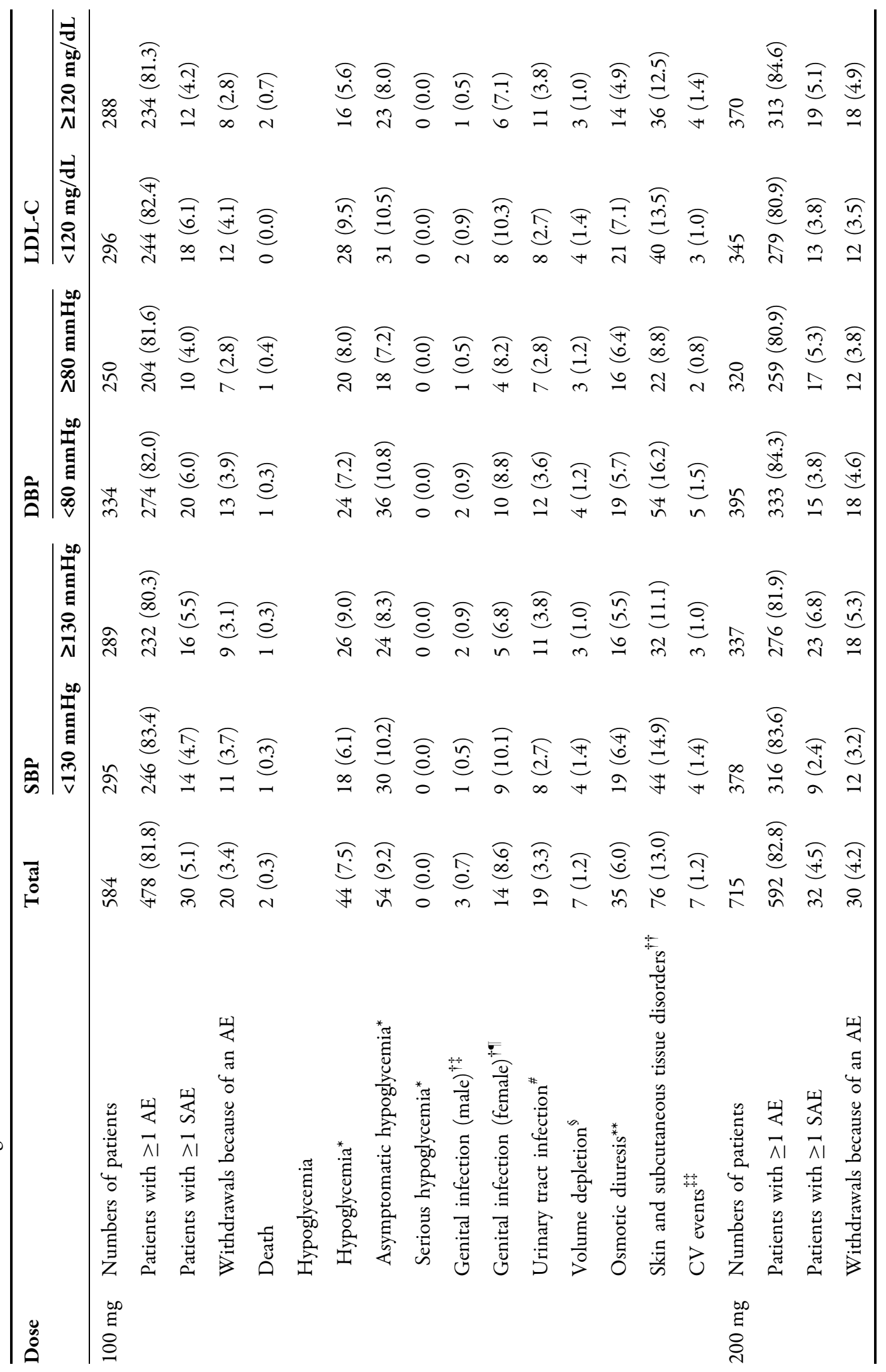




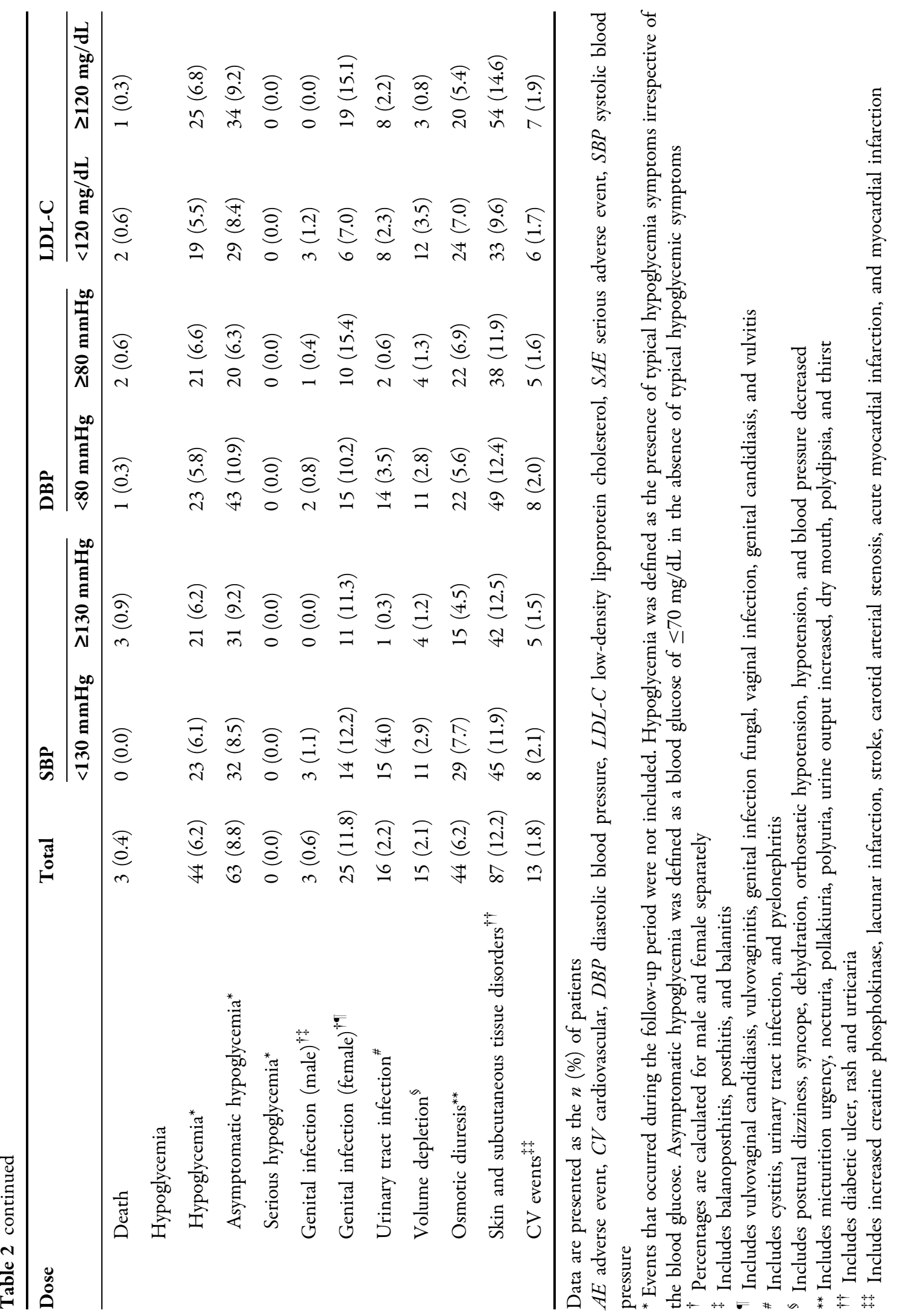




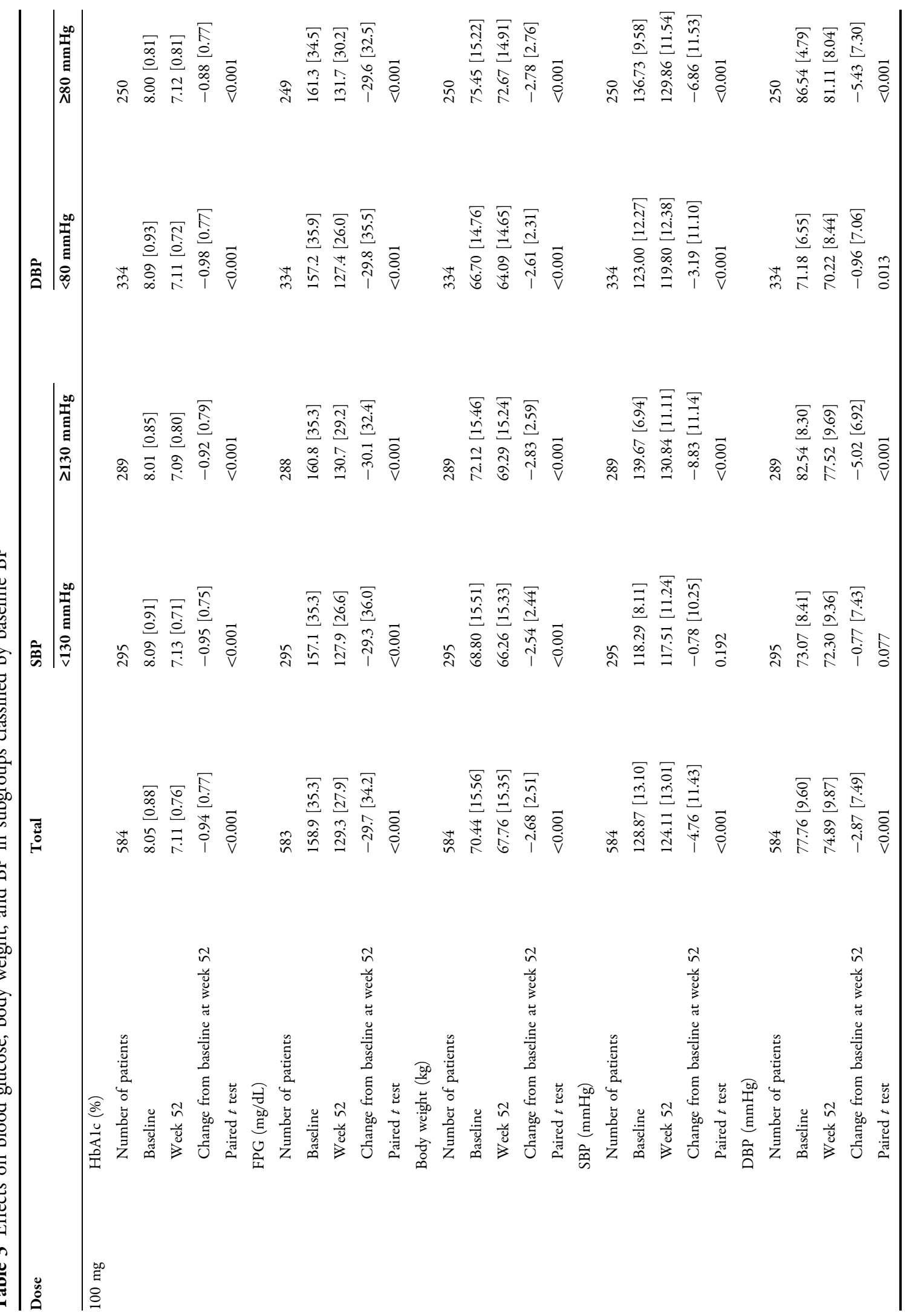




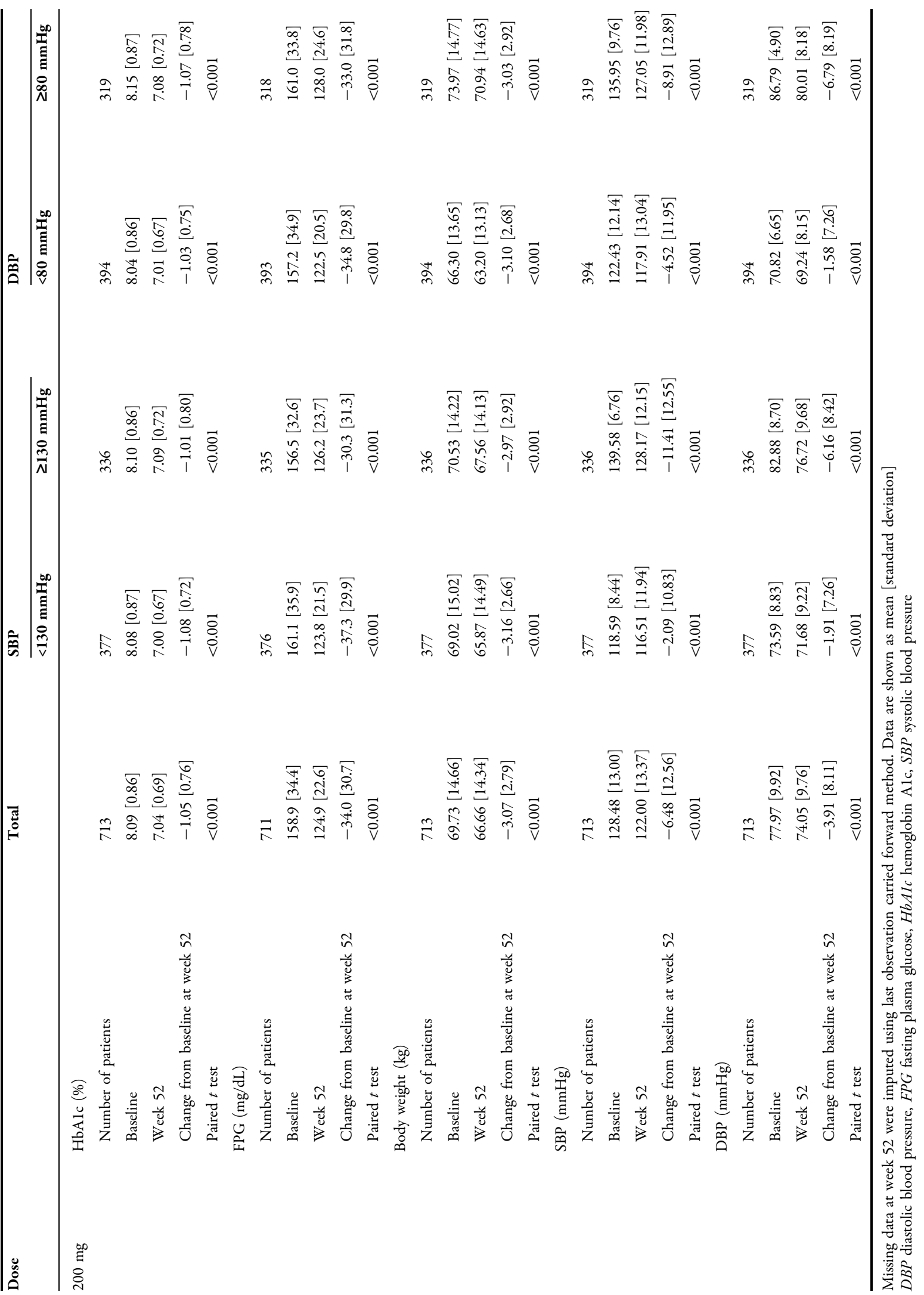


(a) SBP

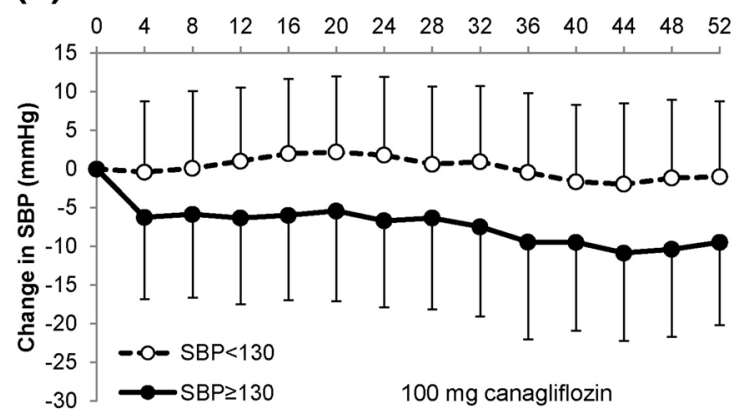

(b) DBP

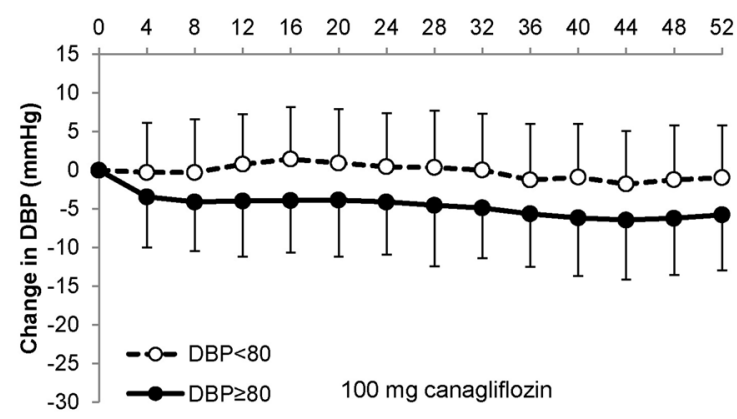

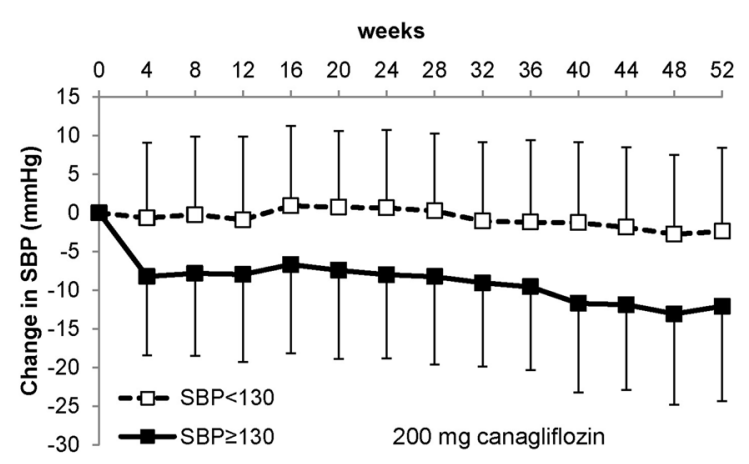

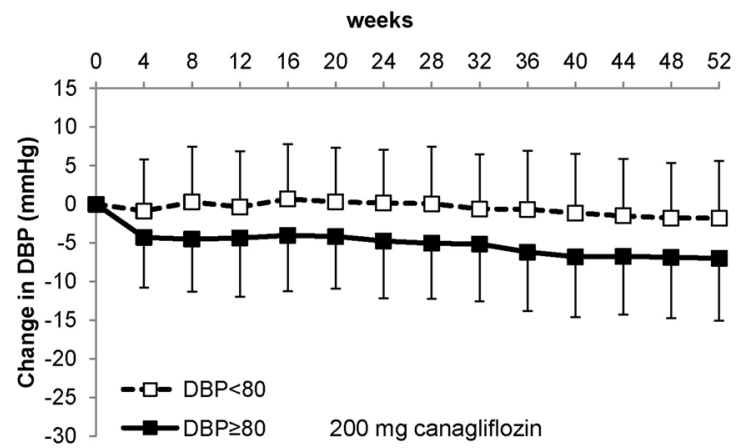

Fig. 1 Changes in SBP (a) and DBP (b) over time in subgroups classified by BP. Each point and bar represent mean and standard deviation, respectively. $B P$ blood pressure, $D B P$ diastolic blood pressure, $S B P$ systolic blood pressure

administration of canagliflozin at both doses (Fig. 1; Table 3). In $S \geq 130$ subgroups, the proportions of patients whose SBP decreased to $<130 \mathrm{mmHg}$ were $43.6 \%$ and $57.1 \%$ after the 52 -week administration at $100 \mathrm{mg}$ and $200 \mathrm{mg}$ doses, respectively. In $D \geq 80$ subgroups, the proportions of patients whose DBP decreased to $<80 \mathrm{mmHg}$ were also $42.0 \%$ and $47.3 \%$ at 100 and $200 \mathrm{mg}$ doses, respectively. The BP-lowering effect of canagliflozin was not affected by combined treatment of antihypertensive agents at baseline (data not shown).

\section{Analysis in Subgroups Classified by Baseline LDL-C}

Patient characteristics of subgroups classified by baseline LDL-C are shown in Table 4 . The number of patients was almost the same in each subgroup.

Table 2 summarizes the AEs in each subgroup. No differences were observed in the incidence rate of total AEs and SAEs in both subgroups at either dose of canagliflozin. No differences were observed in the incidence rate of AEs resulting in study discontinuation. The frequency of female genital infection in AEs was $7.0 \%$ and $15.1 \%$ in $L<120$ subgroup and $L \geq 120$ subgroup at the $200 \mathrm{mg}$ dose, respectively, whereas it was similar between $L<120$ and $L \geq 120$ subgroups at the $100 \mathrm{mg}$ dose (Table 2).

Of 15 patients with volume depletion-related AEs at the $200 \mathrm{mg}$ dose, 12 and 3 were in $L<120$ and $L \geq 120$ subgroups, respectively. Of the 12 volume depletion-related AEs in the 
Table 4 Demographics and baseline characteristics of patients in subgroups classified by baseline LDL-C

\begin{tabular}{|c|c|c|c|c|c|c|}
\hline \multirow{3}{*}{$\begin{array}{l}\text { Dose } \\
\text { Characteristic }\end{array}$} & \multicolumn{3}{|l|}{$100 \mathrm{mg}$} & \multicolumn{3}{|l|}{$200 \mathrm{mg}$} \\
\hline & \multirow[t]{2}{*}{ Total } & \multicolumn{2}{|l|}{ LDL-C } & \multirow[t]{2}{*}{ Total } & \multicolumn{2}{|l|}{ LDL-C } \\
\hline & & $<120 \mathrm{mg} / \mathrm{dL}$ & $\geq 120 \mathrm{mg} / \mathrm{dL}$ & & $<120 \mathrm{mg} / \mathrm{dL}$ & $\geq 120 \mathrm{mg} / \mathrm{dL}$ \\
\hline Number of patients & 584 & 296 & 288 & 715 & 345 & 370 \\
\hline \multicolumn{7}{|l|}{ Sex* } \\
\hline Male & $421(72.1)$ & $218(73.6)$ & $203(70.5)$ & $503(70.3)$ & $259(75.1)$ & $244(65.9)$ \\
\hline Female & $163(27.9)$ & $78(26.4)$ & $85(29.5)$ & $212(29.7)$ & $86(24.9)$ & $126(34.1)$ \\
\hline Monotherapy* & $127(21.7)$ & $57(19.3)$ & $70(24.3)$ & $253(35.4)$ & $114(33.0)$ & $139(37.6)$ \\
\hline Combination therapy* & $457(78.3)$ & $239(80.7)$ & $218(75.7)$ & $462(64.6)$ & $231(67.0)$ & $231(62.4)$ \\
\hline With diabetic complications ${ }^{* \dagger}$ & $176(30.1)$ & $90(30.4)$ & $86(29.9)$ & $211(29.5)$ & $104(30.1)$ & $107(28.9)$ \\
\hline With hypertension* & $315(53.9)$ & $166(56.1)$ & $149(51.7)$ & $375(52.4)$ & $171(49.6)$ & $204(55.1)$ \\
\hline With dyslipidemia* & $445(76.2)$ & $214(72.3)$ & $231(80.2)$ & $538(75.2)$ & $242(70.1)$ & $296(80.0)$ \\
\hline \multicolumn{7}{|c|}{ Concomitant antihyperlipidemic agent } \\
\hline Statin* & $191(32.7)$ & $132(44.6)$ & $59(20.5)$ & $215(30.1)$ & $146(42.3)$ & $69(18.6)$ \\
\hline Age (years) ${ }^{*}$ & $57.5[10.7]$ & $58.5[10.9]$ & $56.5[10.3]$ & $57.9[11.1]$ & $58.5[10.7]$ & $57.2[11.4]$ \\
\hline Duration (years) ${ }^{\ddagger}$ & $6.45[5.93]$ & $6.91[6.45]$ & $5.99[5.33]$ & $5.99[5.67]$ & $6.42[6.37]$ & $5.59[4.91]$ \\
\hline Body weight $(\mathrm{kg})^{\ddagger}$ & $70.44[15.56]$ & $69.75[15.74]$ & $71.16[15.37]$ & $69.74[14.64]$ & $69.44[14.94]$ & $70.02[14.38]$ \\
\hline Body mass index $\left(\mathrm{kg} / \mathrm{m}^{2}\right)^{\ddagger}$ & $25.89[4.65]$ & $25.53[4.72]$ & $26.25[4.56]$ & $25.74[4.37]$ & $25.37[4.29]$ & $26.08[4.43]$ \\
\hline $\mathrm{HbAlc}(\%)^{\ddagger}$ & $8.05[0.88]$ & $8.04[0.89]$ & $8.06[0.87]$ & $8.09[0.86]$ & $8.06[0.85]$ & $8.12[0.87]$ \\
\hline FPG $(\mathrm{mg} / \mathrm{dL})^{\ddagger}$ & $158.9[35.3]$ & $156.4[34.0]$ & $161.5[36.6]$ & $159.0[34.4]$ & $157.2[32.6]$ & $160.7[36.0]$ \\
\hline
\end{tabular}

FPG fasting plasma glucose, $L D L$-C low-density lipoprotein cholesterol, $H b A 1 c$ hemoglobin Alc

${ }^{*}$ Data are presented as the $n(\%)$ of patients

$\dagger$ Diabetic nephropathy, diabetic neuropathy and diabetic retinopathy

* Data are presented as the mean [standard deviation]

$L<120$ subgroup, 7 had mild postural dizziness and 4 had dehydration (data not shown).

No clear differences were observed in the incidence rates of other AEs and drug-related AEs between the subgroups classified by baseline LDL-C (Table 2 and Table S1). Changes of laboratory variables from baseline to week 52 were similar between subgroups at both doses of canagliflozin (see Table S3 in the ESM).

HbA1c, FPG, and body weight significantly decreased from baseline to week 52 of treatment with canagliflozin in both subgroups (Table 5). In $L<120$ subgroup, LDL-C slightly increased but did not exceed $120 \mathrm{mg} / \mathrm{dL}$ after a 52-week administration of either dose (Table 5; Fig. 2). This LDL-C increase was maintained until week 52. On the other hand, LDL-C in $L \geq 120$ subgroup slightly decreased from baseline after administrations of canagliflozin at both doses (Table 5). Triglyceride decreased from baseline to week 52, except for $L<120$ subgroup at the $100 \mathrm{mg}$ dose. HDL-C increased after the 52-week administration to a similar extent in 


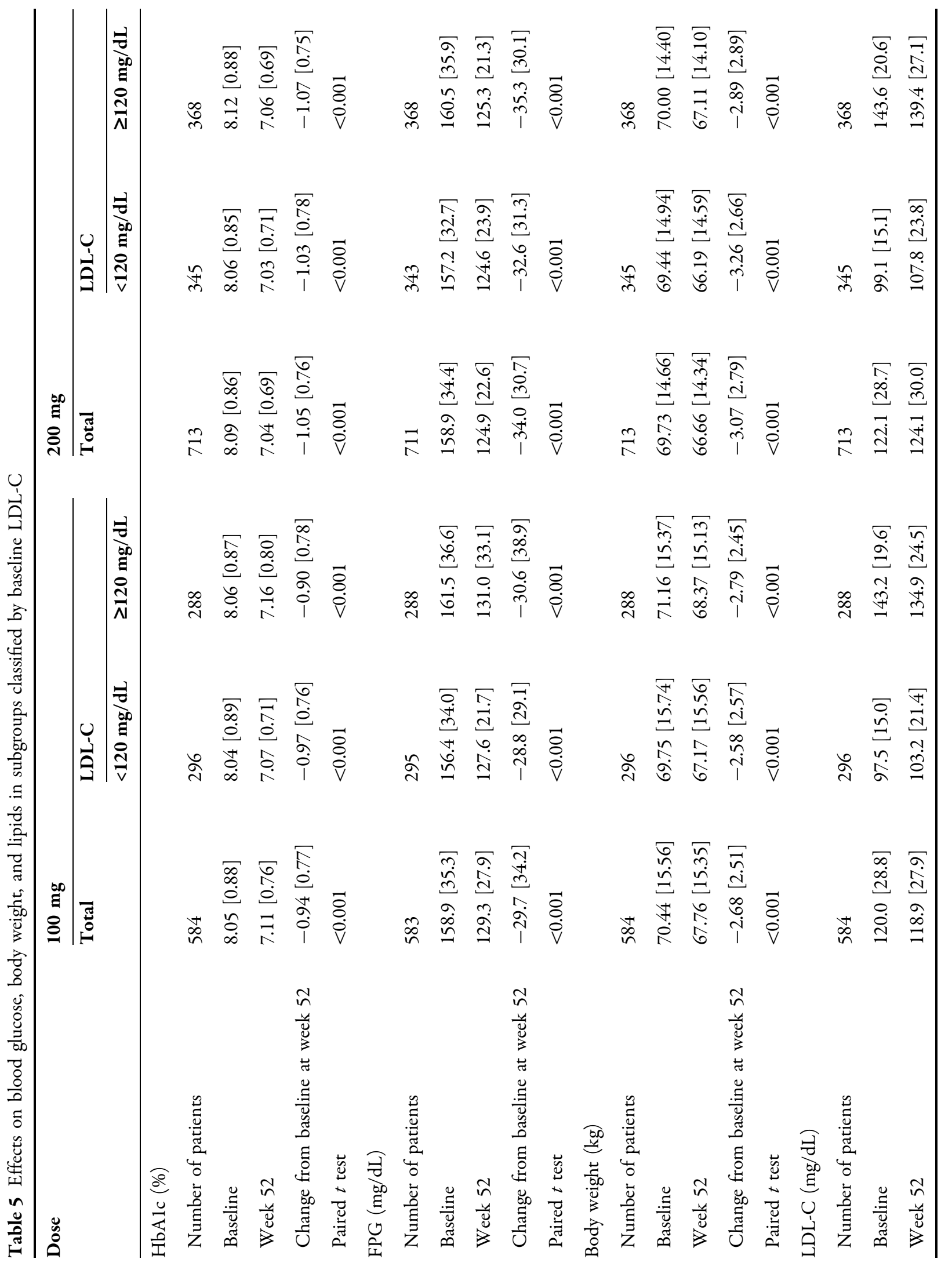




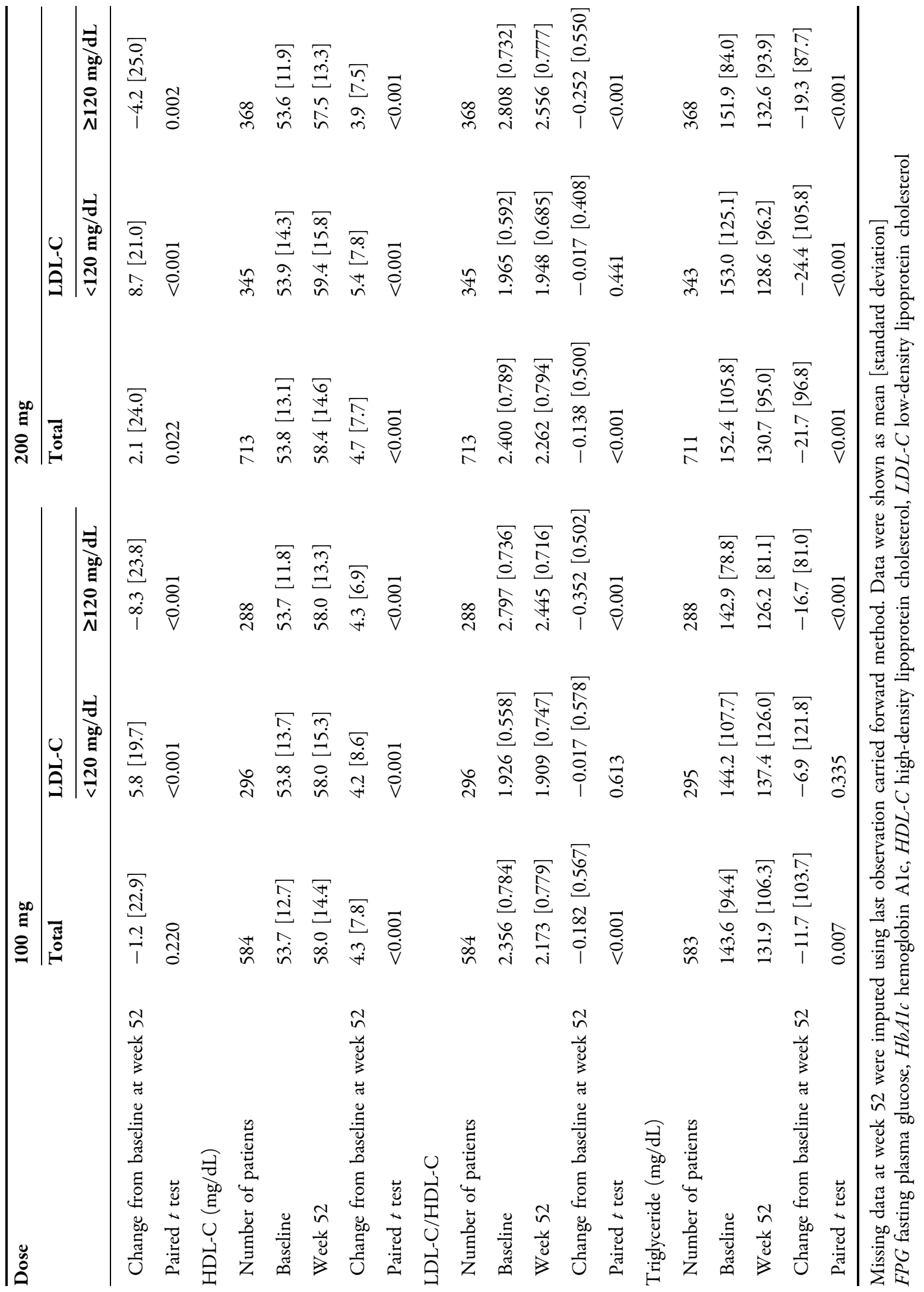



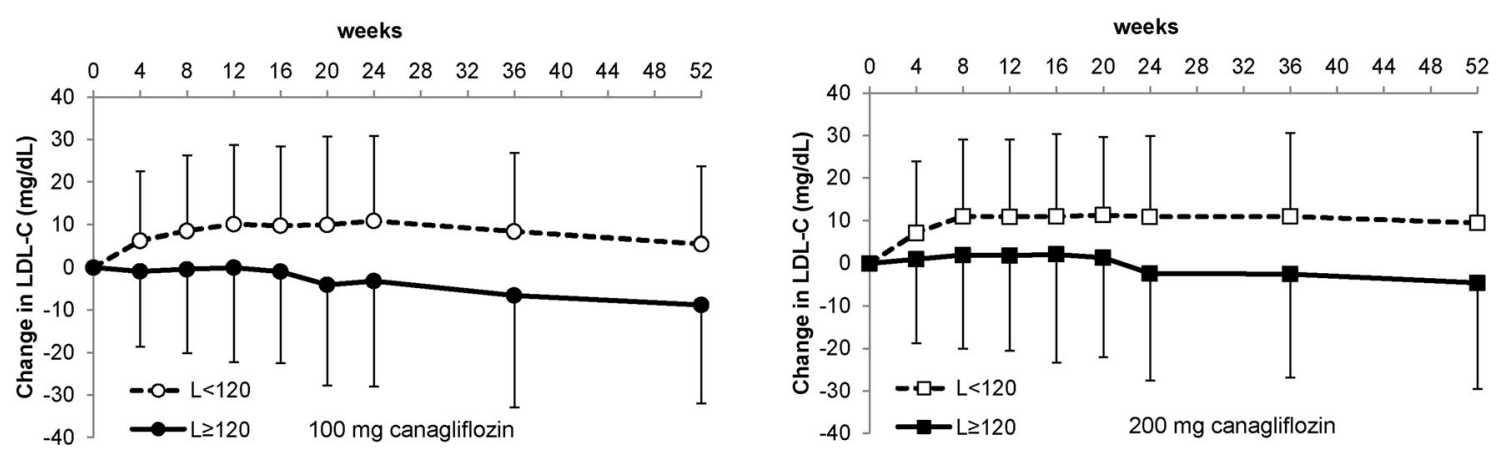

Fig. 2 Change in LDL-C over time in subgroups classified by LDL-C. Each point and bar represent mean and standard deviation, respectively. $L D L-C$ low-density lipoprotein cholesterol

these subgroups. LDL-C/HDL-C was unchanged in $L<120$ subgroup, but it slightly decreased in $L \geq 120$ subgroup at both canagliflozin doses.

\section{DISCUSSION}

Hypertension and hypercholesterolemia are common comorbid conditions in many patients with T2DM [18], and canagliflozin affects BP and lipid parameters. Therefore, in this report, we examined the safety and efficacy of canagliflozin in post hoc subgroup analyses in which patients were classified subgroups of different baseline of BP and LDL-C using data from a 52-week randomized open-label study in Japanese patients with T2DM [13]. In the present subgroup analyses, the total incidence of AEs and drug-related AEs was not generally different between BP and LDL-C subgroups. There were some imbalances in incidence rates of AEs between the subgroups according to SBP, DBP, or LDL-C at the $200 \mathrm{mg}$ dose. The incidence rate of urinary tract infections or volume depletion-related AEs was frequent in $S<130$ and $D<80$ subgroups at $200 \mathrm{mg}$ dose. In the LDL-C subgroup analysis, occurrence of volume depletion-related or female genital infection-related AEs was frequent in the $L<120$ or $L \geq 120$ subgroups, respectively, at the $200 \mathrm{mg}$ dose. However, AEs related to urinary tract infections, volume depletion, or female genital infections occurred with other SGLT2 inhibitors at an incidence rate of approximately $0-7.4 \%, 0-4.4 \%$, or $0-22.2 \%$, respectively [19-25]. Therefore, the incident rates of canagliflozin-associated AEs in this study were within the expected range for SGLT2 inhibitors. The reasons for the difference in the incidence of urinary infections or female genital infection-related AEs between subgroups at $200 \mathrm{mg}$ doses are unknown, and there is no evidence which have shown the association between urinary tract infections and BP, or between female genital infections and LDL-C.

The incidence of volume depletion-related AEs was evident at $200 \mathrm{mg}$, particularly in the $S<130, D<80$, and $L<120$ subgroups. Baseline characteristics of 15 patients with volume depletion-related AEs were age of 38-72 years old and eGFR of $62-104 \mathrm{~mL} / \mathrm{min} / 1.73 \mathrm{~m}^{2}$. No patients received loop diuretics and the time to the first AEs varied over the study period. Eight of 15 patients were with SBP $<130 \mathrm{mmHg}$ and LDL-C $<120 \mathrm{mg} / \mathrm{dL}$ and 8 patients were with DBP $<80 \mathrm{mmHg}$ and LDL-C $<120 \mathrm{mg} / \mathrm{dL}$. On the other hand, volume depletion-related AEs did not occur in patients with SBP $\geq 130 \mathrm{mmHg}$ and LDL-C $\geq 120 \mathrm{mg} / \mathrm{dL}$. The reason for the high frequency of volume depletion-related AEs 
in the patients in the lower BP or LDL-C subgroups at $200 \mathrm{mg}$ dose is unclear. With regard to $\mathrm{BP}$, it is possible that the patients with volume depletion-related AEs in the lower BP subgroups might be susceptible to the diuretic effects of canagliflozin; however, there were insufficient data to discuss this. A previous study has shown that canagliflozin increased the incidence rate of volume depletion in elderly patients ( $>75$ years old), patients with eGFR $<60 \mathrm{~mL} / \mathrm{min} / 1.73 \mathrm{~m}^{2}$, and those on diuretic therapy [26], which do not correspond to the baseline characteristics of the patients with volume depletion-related AEs in the present study. Although volume depletion should be carefully considered in elderly patients, patients with renal impairment, and those receiving loop diuretic therapies, the severity of the volume depletion-related AEs was mild in the patients in the present study.

Efficacy was similar in the overall group and subgroups, except for BP in the SBP and DBP subgroups and lipid profiles in the LDL-C subgroups. In overall patients, canagliflozin slightly reduced SBP and DBP from baseline. The changes in SBP and DBP from baseline were evident in the $S \geq 130$ subgroups after starting treatment with canagliflozin at the $100 \mathrm{mg}$ and $200 \mathrm{mg}$ doses. These results are consistent with a report of more evident decreases in mean BP with SBP $\geq 140 \mathrm{mmHg}$ than in the overall population after a 26-week administration of canagliflozin [27]. In the $S \geq 130$ and $D \geq 80$ subgroups at both doses, $>40 \%$ of patients achieved SBP $<130 \mathrm{mmHg}$ and DBP $<80 \mathrm{mmHg}$ at 52 weeks. In addition, the BP-lowering effect of canagliflozin was independent of combined treatment with antihypertensive agents at baseline. According to the guidelines for treatment of T2DM, the target level of BP control is SBP $<130 \mathrm{mmHg}$ and DBP $<80 \mathrm{mmHg}$ in patients with diabetes
[8]. Therefore, the results indicate that canagliflozin is beneficial in the treatment of patients with T2DM with hypertension.

Although there were no changes in LDL-C in the overall patients, LDL-C over those observed at baseline increased in the $L<120$ subgroups and decreased in the $L \geq 120$ subgroup at both 100 and $200 \mathrm{mg}$ canagliflozin. The present study, baseline LDL-C in the $L<120$ subgroups at both 100 and $200 \mathrm{mg}$ canagliflozin were 97.5 and $99.1 \mathrm{mg} / \mathrm{dL}$, respectively, was consistent with previous reports: dapagliflozin or empagliflozin increased LDL-C in patients with baseline LDL-C between 90 and $110 \mathrm{mg} / \mathrm{dL}$ [16]. The change in LDL-C was observed at 4 weeks of initiation of treatment although the mean LDL-C did not reach $120 \mathrm{mg} / \mathrm{dL}$ throughout the treatment period. HDL-C in the overall, $L<120$, and $L \geq 120$ subgroups similarly increased. The triglyceride were decreased in the overall and $L \geq 120$ subgroup at the $100 \mathrm{mg}$ dose and the overall, $L \geq 120$, and $L<120$ subgroups at the $200 \mathrm{mg}$ dose. The effects of canagliflozin on lipid metabolism may be mediated through urinary caloric loss by SGLT2 inhibition. Although further investigation is necessary to clarify the mechanism on lipid metabolism, it should be stressed that canagliflozin did not increase the risk of LDL-C elevation in $L \geq 120$ subgroup. Indeed, empagliflozin was associated with small increases in LDL-C in the EMPA-REG OUTCOME trial; however, $\mathrm{CV}$ risk was reduced in the empagliflozin treated group, as compared with placebo group [15].

The limitations of the study are described as follows: (1) this 52-week study was conducted in an open-label manner and the present results are derived from post hoc sub-analyses of the original data and (2) the study scale and treatment period were insufficient to evaluate risks of $\mathrm{CV}$ events for antidiabetic agents. To 
assess the effect of canagliflozin on the CV risk, the CANVAS (CANagliflozin cardioVascular Assessment Study; ClincalTrials.gov identifier, NCT01032629) clinical trial is now in progress in patients with high risk of heart diseases [28]. The effects of SGLT2 inhibitors on the risk of CV events should be further evaluated.

\section{CONCLUSIONS}

This post hoc analysis indicates that canagliflozin at 100 and $200 \mathrm{mg}$ reduces HbA1c, FPG, body weight, and triglyceride, and increases HDL-C across subgroups classified according to baseline SBP, DBP, and LDL-C in a 52-week phase III study in Japanese patients with T2DM. Reduction in BP was evident in $S \geq 130$ and $D \geq 80$ subgroups. LDL-C was decreased in the $L \geq 120$ subgroup and was slightly increased but did not exceed $120 \mathrm{mg} / \mathrm{dL}$ in the $L<120$ subgroup. No clear differences were observed in overall safety among the subgroups except for a slight difference in AEs associated with volume depletion, mainly postural dizziness, with $200 \mathrm{mg}$ of canagliflozin. Therefore, canagliflozin is well tolerated irrespective of baseline BP and LDL-C in patients with T2DM.

\section{ACKNOWLEDGMENTS}

This study was funded by Mitsubishi Tanabe Pharma Corp. The article processing charges and open access fee for this publication were funded by Mitsubishi Tanabe Pharma Corp. The authors thank to Dr. A. Saito, of Tanabe R\&D service Co., Ltd., for providing editorial support, which was funded by Mitsubishi Tanabe Pharma Corp. The authors thank Ms. K. Sasaki for insightful discussions. The authors thank all investigators, study team, and patients for participating in this study. Canagliflozin was developed by Mitsubishi Tanabe Pharma Corp. in collaboration with Janssen Research and Development, LLC. All named authors meet the International Committee of Medical Journal Editors (ICMJE) criteria for authorship for this manuscript, take responsibility for the integrity of the work as a whole, and have given final approval for the version to be published.

Disclosures. N. Inagaki has received consulting fees and research support from Mitsubishi Tanabe Pharma Corp., and has served on speakers bureaus for Mitsubishi Tanabe Pharma Corp. He has also received consulting fees and/or research support from Astellas Pharma Inc., AstraZeneca K.K., Bristol-Myers K.K., Chugai Pharmaceutical Co., Ltd., Daiichi Sankyo Co., Ltd., Eisai Co., Ltd., Eli Lilly Japan K.K., GlaxoSmithKline K.K., Japan Tobacco Inc., Kissei Pharmaceutical Co., Ltd., Kyowa Hakko Kirin Co., Ltd., MSD K.K., Nippon Boehringer Ingelheim Co., Ltd., Nipro Corporation, Novartis Pharma K.K., Novo Nordisk Pharma Ltd., Ono Pharmaceutical Co., Ltd., Pfizer Japan Inc., Roche Diagnostics K.K., Sanofi K.K., Sanwa Kagaku Kenkyusho Co., Ltd., Shionogi and Co., Ltd., Shiratori Pharmaceutical Co., Ltd., Sumitomo Dainippon Pharma Co., Ltd., Taisho Pharmaceutical Co., Ltd., and Takeda Pharmaceutical Co., Ltd., Terumo Corporation, and Tsumura and Co.; and has served on speakers bureaus for ARKRAY, Inc., Astellas Pharma Inc., AstraZeneca K.K., Bayer Yakuhin, Ltd., Daiichi Sankyo Co., Ltd., Eisai Co., Ltd., Eli Lilly Japan K.K., Japan Tobacco Inc., Johnson and Johnson K.K., Kissei Pharmaceutical Co., Ltd., Kowa Pharmaceutical Co., Ltd., Kyowa Hakko Kirin Co., Ltd., Medtronic, Inc., MSD K.K., Nippon Boehringer Ingelheim Co., Ltd., Novartis Pharma K.K., Novo Nordisk Pharma Ltd., Ono Pharmaceutical Co., 
Ltd., Roche Diagnostics K.K., Sanofi K.K., Sanwa Kagaku Kenkyusho Co., Ltd., Sumitomo Dainippon Pharma Co., Ltd., Taisho Toyama Pharmaceutical Co., Ltd., and Takeda Pharmaceutical Co., Ltd. and Tsumura and Co. M. Goda is an employee of Mitsubishi Tanabe Pharma Corporation. S. Yokota is an employee of Mitsubishi Tanabe Pharma Corporation. $\mathrm{N}$. Maruyama is an employee of Mitsubishi Tanabe Pharma Corporation. H. Iijima is an employee of Mitsubishi Tanabe Pharma Corporation.

Compliance with ethics guidelines. All procedures followed were in accordance with the ethical standards of the relevant committee on human experimentation (institutional and national) and with the Helsinki Declaration of 1964, as revised in 2013. Informed consent was obtained from all patients for study participation.

Open Access. This article is distributed under the terms of the Creative Commons Attribution-NonCommercial 4.0 International License (http://creativecommons.org/licenses/ by-nc/4.0/), which permits any noncommercial use, distribution, and reproduction in any medium, provided you give appropriate credit to the original author(s) and the source, provide a link to the Creative Commons license, and indicate if changes were made.

\section{REFERENCES}

1. Stamler J, Vaccaro O, Neaton JD, Wentworth D. Diabetes, other risk factors, and 12-yr cardiovascular mortality for men screened in the Multiple Risk Factor Intervention Trial. Diabetes Care. 1993;16:434-44.

2. Sone H, Katagiri A, Ishibashi S, et al. Effects of lifestyle modifications on patients with type 2 diabetes: the Japan Diabetes Complications Study (JDCS) study design, baseline analysis and three year-interim report. Horm Metab Res. 2002;34:509-15.

3. Oikawa S, Kita T, Mabuchi H, et al. Risk of coronary events in Japanese patients with both hypercholesterolemia and type 2 diabetes mellitus on low-dose simvastatin therapy: implication from Japan Lipid Intervention Trial (J-LIT). Atherosclerosis. 2007;191:440-6.

4. American Diabetes Association. Role of cardiovascular risk factors in prevention and treatment of macrovascular disease in diabetes. Diabetes Care. 1989;12:573-9.

5. Gaede P, Lund-Andersen H, Parving HH, Pedersen O. Effect of a multifactorial intervention on mortality in type 2 diabetes. $\mathrm{N}$ Engl J Med. 2008;358:580-91.

6. UK Prospective Diabetes Study Group. Tight blood pressure control and risk of macrovascular and microvascular complications in type 2 diabetes: UKPDS 38. BMJ. 1998;317:703-13.

7. American Diabetes Association. Standards of medical care in diabetes-2015: summary of revisions. Diabetes Care. 2015;38:S4.

8. The Japan Diabetes Society. Evidence-based Practice Guideline for the Treatment for Diabetes in Japan. http://www.jds.or.jp/modules/en/index. php?content_id=44. 2013. Accessed 30 Oct 2015.

9. Stenlof K, Cefalu WT, Kim KA, et al. Efficacy and safety of canagliflozin monotherapy in subjects with type 2 diabetes mellitus inadequately controlled with diet and exercise. Diabetes Obes Metab. 2013;15:372-82.

10. Cefalu WT, Leiter LA, Yoon KH, et al. Efficacy and safety of canagliflozin versus glimepiride in patients with type 2 diabetes inadequately controlled with metformin (CANTATA-SU): 52 week results from a randomised, double-blind, phase 3 non-inferiority trial. Lancet. 2013;382:941-50.

11. Leiter LA, Yoon KH, Arias $\mathrm{P}$, et al. Canagliflozin provides durable glycemic improvements and body weight reduction over 104 weeks versus glimepiride in patients with type 2 diabetes on metformin: a randomized, double-blind, phase 3 study. Diabetes Care. 2015;38:355-64.

12. Lavalle-Gonzalez FJ, Januszewicz A, Davidson J, et al. Efficacy and safety of canagliflozin compared with placebo and sitagliptin in patients with type 2 diabetes on background metformin monotherapy: a randomised trial. Diabetologia. 2013;56:2582-92.

13. Inagaki N, Kondo K, Yoshinari T, Kuki H. Efficacy and safety of canagliflozin alone or as add-on to 
other oral antihyperglycemic drugs in Japanese patients with type 2 diabetes: a 52-week open-label study. J Diabetes Investig. 2015;6:210-8.

14. Inagaki N, Kondo $\mathrm{K}$, Yoshinari $\mathrm{T}$, Takahashi N, Susuta Y, Kuki H. Efficacy and safety of canagliflozin monotherapy in Japanese patients with type 2 diabetes inadequately controlled with diet and exercise: a 24-week, randomized, double-blind, placebo-controlled, Phase III study. Expert Opin Pharmacother. 2014;15:1501-15.

15. Zinman B, Wanner C, Lachin JM, et al. Empagliflozin, cardiovascular outcomes, and mortality in type 2 diabetes. $\mathrm{N}$ Engl J Med. 2015;15:1501-15. doi:10.1056/NEJMoa1504720.

16. Halimi S, Verges B. Adverse effects and safety of SGLT-2 inhibitors. Diabetes Metab. 2014;40:S28-34.

17. Inzucchi SE, Zinman B, Wanner C, et al. SGLT-2 inhibitors and cardiovascular risk: proposed pathways and review of ongoing outcome trials. Diab Vasc Dis Res. 2015;12:90-100.

18. Center for Disaese Control and Prevention. National diabetes statics report. 2014. http://www. cdc.gov/diabetes/pubs/statsreport14/national-diabetesreport-web.pdf.

19. Kaku $\mathrm{K}$, Maegawa $\mathrm{H}$, Tanizawa $\mathrm{Y}$, et al. Dapagliflozin as monotherapy or combination therapy in Japanese patients with type 2 diabetes: an open-label study. Diabetes Ther. 2014;5:415-33.

20. Araki E, Tanizawa Y, Tanaka Y, et al. Long-term treatment with empagliflozin as add-on to oral antidiabetes therapy in Japanese patients with type 2 diabetes mellitus. Diabetes Obes Metab. 2015;17:665-74.

21. Tanizawa $Y$, Kaku K, Araki E, et al. Long-term safety and efficacy of tofogliflozin, a selective inhibitor of sodium-glucose cotransporter 2 , as monotherapy or in combination with other oral antidiabetic agents in Japanese patients with type 2 diabetes mellitus: multicenter, open-label, randomized controlled trials. Expert Opin Pharmacother. 2014;15:749-66.

22. Ikeda S, Takano Y, Cynshi O, et al. A novel and selective sodium-glucose cotransporter-2 inhibitor, tofogliflozin, improves glycaemic control and lowers body weight in patients with type 2 diabetes mellitus. Diabetes Obes Metab. 2015. doi:10.1111/dom.12538.

23. Seino Y, Kaku K, Inagaki N, et al. Fifty-two-week long-term clinical study of luseogliflozin as monotherapy in Japanese patients with type 2 diabetes mellitus inadequately controlled with diet and exercise. Endocr J. 2015;62:593-603.

24. Seino $\mathrm{Y}$, Inagaki $\mathrm{N}$, Haneda $\mathrm{M}$, et al. Efficacy and safety of luseogliflozin added to various oral antidiabetic drugs in Japanese patients with type 2 diabetes mellitus. J Diabetes Investig. 2015;6:443-53.

25. Kadowaki T, Haneda M, Inagaki N, et al. Efficacy and safety of empagliflozin monotherapy for 52 weeks in Japanese patients with type 2 diabetes: a randomized, double-blind, parallel-group study. Adv Ther. 2015;32:306-18.

26. Mikhail N. Safety of canagliflozin in patients with type 2 diabetes. Curr Drug Saf. 2014;9:127-32.

27. Weir MR, Januszewicz A, Gilbert RE, et al. Effect of canagliflozin on blood pressure and adverse events related to osmotic diuresis and reduced intravascular volume in patients with type 2 diabetes mellitus. J Clin Hypertens (Greenwich). 2014;16:875-82.

28. Neal B, Perkovic V, de Zeeuw D, et al. Rationale, design, and baseline characteristics of the Canagliflozin Cardiovascular Assessment Study (CANVAS) - a randomized placebo-controlled trial. Am Heart J. 2013;166:217-223.e211. 